are most important in those particulars in which they are able to state that they have established a pressor effect of tissues when injected into the circulation. My own efforts at attempting to discover variations in the effects following the injection of tissues in various pathological conditions were followed merely by the observation that in practically all cases there was but one effect-namely, a depressor one; occasionally the injection of a preparation would produce a brief rise, much as does the simple injectien of saline solution in some cases, though as a rule this latter solution generally causes a slight fall. However, a careful reperusal of Swale Vincent and Sheen's paper impressed me that the organs removed from individuals dying from
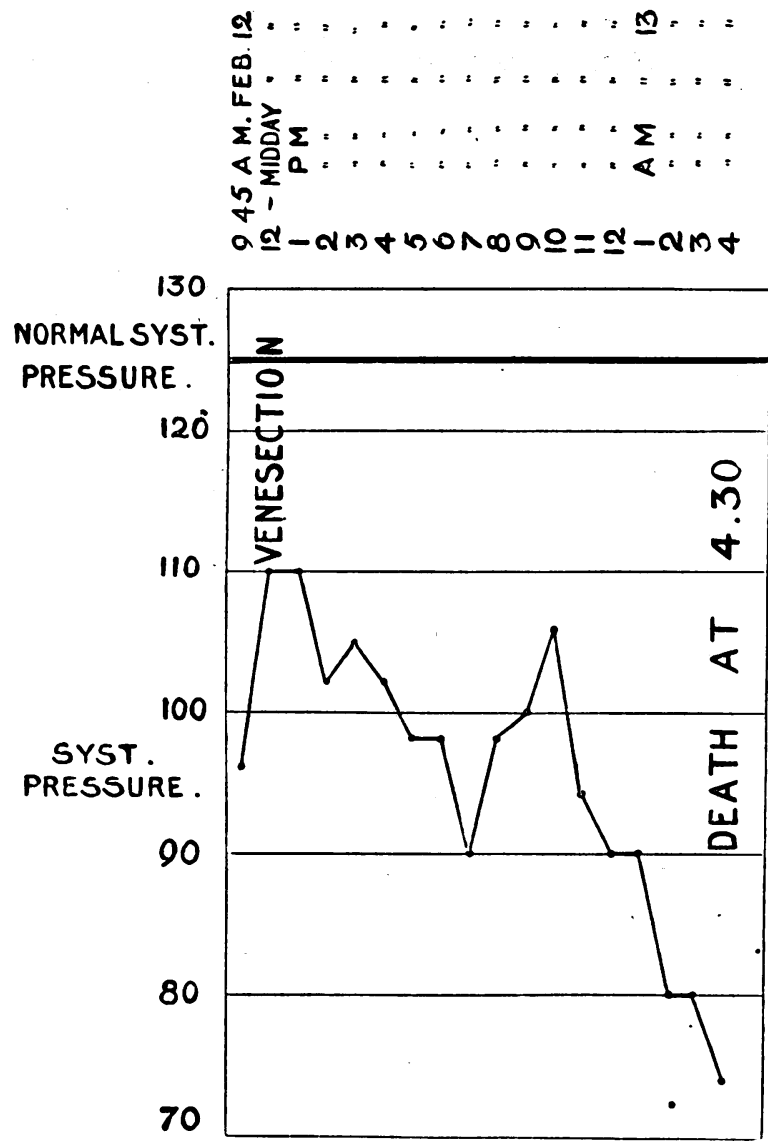

Chart 11.-Case XII, a widow, aged 49; chronic Bright's disease.

different diseases were not fresh tissues, although keeping the bodies in an ice chamber had prevented their putre faction. Moreover, suspicions were aroused that possibly post-mortem softening might have so affected the reactions of the fresh tissues that, supposing any pressor substances had been present in the organs of the patient who had died, such active agent would have disappeared. At this time I was very materially helped by Dr. Schryder, who pointed out to me a certain period subsequent to the removal of tissues from animals in which the tissues do not undergo chemical change. An appeal, therefore, was made to the effects of fresh tissues removed from a cat and after preparation injected into another.

[Dr. Shaw then described the method of his experiment, and gave a summary of his results as follows:]

The first series of experiments carried out in the above way include those animals in which several differen tissue extracts were injected into the same animal; it consisted of eight experiments carried out on eight animals. There are six experiments left for consideration [after he had excluded two for accidental reasons]. Injection of spleen gave a rise of pressure on three occasions of $18 \mathrm{~mm}$., $2 \mathrm{~mm}$., $8 \mathrm{~mm}$., lasting respectively 45 seconds, 10 minutes, 30 seconds; a fall occurred in 2 cases of $4 \mathrm{~mm}$., lasting 1 to 2 seconds, and of $6 \mathrm{~mm}$. lasting 4 seconds. Injection of muscle extract was practised twice; in one there was a marked fall of $38 \mathrm{~mm}$. lasting
4 minutes 28 seconds, and in the other a fall of only $4 \mathrm{~mm}$. lasting 1 minute 55 seconds.

[The observations on the kidney, liver, and brain were more numerous, and the lecturer referred to tables which showed that these organs sometimes caused a rise and sometimes a fall. He then proceeded in conclusion as follows:]

It is obvious that though other organs than the kidney occasionally show a rise of pressure on injection, zet this rise is small and of short duration, whereas the kidney effect of a rise, though varying within considerable limits, is a striking feature, and the same may be said of the duration in which such rise takes place; no other organ has been noticed to have such an effect so frequently. 'The liver and brain show a much greater tendency to cause a fall of blood pressure, and even then such fall is generally of very brief duration. One point to which it is necessary to draw attention is that in none of these experi. ments was the kidney extract injected first; the injection always succeeded that of some other organ, and it may be objected that it is possible that the rise of pressure following the injection of renal extract is due to some interaction of renal extract with some previous extract. Moreover, it may be thought that the renal extract is of a different physical character, and likely to cause a rise of pressure from some mechanical effort dependent upon the granules contained in the emulsion. As will be seen later, there is no reason to believe that either of these objections holds good. It is to be observed that the animals were simply under the influence of ether; this was so carefully administered that the respiration was maintained regularly. In one experiment with ether anaesthesia and artificial respiration the vagi were cut; an injection of renal extract then produced the exceedingly small rise of only 4 or 1 millimetre, lasting one minute, forty seconds, and twenty-five seconds respeetively. So far as this one experiment is concerned, it must be stated that the second injection of an extract has on other occasions shown a less marked reaction than the first one. The slight rise, such as it is, merely suggests that the rise of pressure on injecting renal extract is due to a peripheral effect whereby the arterial pressure is raised.

$$
\text { i Journal of Physiology, 1903, vol. xxix. }
$$

\section{ELCALYPTUS POISONING.}

\section{BY J. ORR, L.R.C.P. AND S.EDIN.,} Templepatrick, co. $\Lambda$ utrim.

Having recently noticed a record of a case of poisoning by eucalyptus oil, I forward notes of a similar case which occurred in my practice on April 16th, 1901. An urgent message was sent to me asking me to visit a little boy aged 2 years and 9 months, who had swallowed 2 drachms of eucalyptus oil. As I was suffering from influenza I could not leave the house, and my locum,tenens was out ou duty; I therefore ordered the child to be brought to me as quickly as possible. This was done, and I sew him about fifteen minutes after he had swallowed the poison. He was unconscious, and collapsed, with a quick pulse, stertorous breathing, and pupils contracted almost to a pin-point, just as in opium poisoning. This pupil contraction, indeed, was the most striking feature in the symptoms. The child had vomited immediately after taking the oil, and purging quickly set in. I gave $10 \mathrm{gr}$. of sulphate of zinc, and, the child having again vomited, I followed this up with a teaspoonful of whisky. The patient still remained in a state of collapse, and as no improvement took place, I thought I would try the effects of strong coffee. A fair amount of this was swallowed by the child, and in a short time the effect was very marked. the pupils began to dilate, and consciousness returned quickly. He was tit to be removed to his home comparatively well an hour after I had first seen him, and made a speedy recovery.

Aт the sixty-first anniversary dinner of the German Hospital, Dalston, on May 7th, it was announced by the Chairman, Count Matternich, German Ambassador, that a new convalescent home combined with an open-air sanatorium. was about to be presented to the institution by certain of its supporters. The necessary land had been acquired near Hitchin, and some $£ 14,000$ contributed for the erection and fitting of the buildings. 